\title{
Chronic HBV infection among pregnant women and their infants in Shenyang, China
}

\author{
Yang Ding, Qiuju Sheng, Li Ma and Xiaoguang Dou*
}

\begin{abstract}
Background: The main transmission route of the hepatitis B virus (HBV) is mother to child transmission and contributes significantly to chronic HBV infection. Even though immunoprophylaxis with hepatitis B immunoglobulin ( $\mathrm{HBIG}$ ) and hepatitis B vaccine is administrated to neonates whose mothers are hepatitis $B$ surface antigen ( $\mathrm{HBs} \mathrm{Ag}$ ) positive, about 10\% of the neonates suffer from HBV infection in their early life.

Objectives: To survey chronic HBV infection among pregnant women and their infants and analyze the reason for immunoprophylaxis failure.

Methods: Serum HBsAg was tested in all pregnant women. HBVDNA and other serum HBV markers including hepatitis B e antigen ( $\mathrm{HBeAg}$ ), hepatitis B core antibody (anti-HBc) and hepatitis B surface antibody (anti-HBs) were tested among HBsAg positive pregnant women. All infants whose mothers were HBsAg positive were vaccinated with a standard immunoprophylaxis. Serum HBV markers and HBVDNA were tested among these infants at 7 months of age. HBV genotypes were analyzed among the infants and pregnant women who were HBVDNA positive.

Results: The prevalence of HBsAg, anti-HBC and anti-HBs among 4,536 pregnant women was 5.49\%, 29.65\% and $58.55 \%$, respectively. The prevalence of HBsAg, anti-HBc and anti-HBs among pregnant women older than 20 years of age was significantly different compared to pregnant women younger than 20 years of age $(4.54,5.69$ and 0.61 times, prevalence older vs. younger, respectively. $P<0.05,0.01,0.05$, respectively). Among $249 \mathrm{HBsAg}$ positive pregnant women, 167 (67.07\%) were HBeAg positive, 204 (81.93\%) were HBVDNA positive and only 37 (14.86\%) had HBVDNA $>10^{7} \mathrm{IU} / \mathrm{ml}$. Among the infants whose mothers were HBsAg positive, 214 (85.94\%) infants were anti-HBs positive. There were 12 (4.82\%) infants who were HBsAg and HBVDNA positive, and all 12 of these infants mothers were HBeAg positive and had HBVDNA $>10^{7} \mathrm{IU} / \mathrm{ml}$. Genotypes B and C were present among 165 pregnant women and genotype $C$ was present in 85 pregnant women. There were 12 infants who were HBsAg positive and had the same HBV genotypes as their mothers. There was a significant difference in genotypes between the pregnant women whose infants were infected with HBV compared to those without HBV infection $(P<0.05)$.
\end{abstract}

Conclusions: There was a significant decline in HBsAg prevalence among pregnant women and their infants in Shenyang. Genotype $\mathrm{C}$ might be a risk factor for mother to child transmission of HBV.

Keywords: HBV, Infection, Pregnancy, Mother to child transmission

\footnotetext{
* Correspondence: zhaoyy@sj-hospital.org

Department of Infectious Diseases, Shengjing Hospital of China Medical University, Shenyang 110004, China
}

\section{() Biomed Central}

(c) 2013 Ding et al.; licensee BioMed Central Ltd. This is an Open Access article distributed under the terms of the Creative Commons Attribution License (http://creativecommons.org/licenses/by/2.0), which permits unrestricted use, distribution, and reproduction in any medium, provided the original work is properly cited. 


\section{Background}

Worldwide, there are about 350 million people with chronic hepatitis $\mathrm{B}$ virus (HBV) infection and about one million deaths per year due to chronic hepatitis, cirrhosis, and hepatocellular carcinoma [1,2]. Mother to child transmission of $\mathrm{HBV}$ is the main transmission route and contributes significantly to chronic HBV infection [3].

China used to be an area of HBV high epidemicity. About $10 \%$ of infants whose mothers were HBV positive suffered from HBV infection in their early life. It has been reported that the prevalence of Hepatitis B surface antigen (HBsAg) has been reduced from 9.75\% in 1992 to $7.18 \%$ in 2006 [4]. In our study, we aimed to survey chronic HBV infection among pregnant women and their infants in Shenyang, China and analyze the reason for immunoprophylaxis failure.

\section{Subjects and methods}

Between June 2010 and November 2011, all pregnant women who delivered at Shengjing Hospital of China Medical University were enrolled. Because immunoprophylaxis with hepatitis B immunoglobulin (HBIG) and hepatitis B vaccine has been universally administrated in Shenyang since 1990, the pregnant women were divided into two age groups: younger than 20 years and older than 20 years of age. Serum HBsAg was tested in all pregnant women. HBVDNA and other serum HBV markers including hepatitis $\mathrm{B}$ e antigen ( $\mathrm{HBeAg}$ ), hepatitis $\mathrm{B}$ core antibody (anti-HBc) and hepatitis B surface antibody (anti-HBs) were tested among HBsAg positive pregnant women.

All infants whose mothers were $\mathrm{HBsAg}$ positive were vaccinated with hepatitis B vaccine 20 ug (Changchun Biotech Research Institute, Changchun, China) according to a standard vaccination regimen (within $12 \mathrm{~h}$ of birth, at week 4, and week 24) and 200 IU doses of HBIG (Hualan Biotech Research Institute, Xinxiang, China) immediately (within $2 \mathrm{~h}$ of birth) and at day 15 .
These infants were followed up at 7 months of age. Serum HBV markers and HBVDNA were tested. HBV genotypes were tested among the infants and pregnant women who were HBVDNA positive.

HBV markers were quantitatively assayed with a chemiluminescent microparticle immunoassay using an automated Abbott AxSYM analyser (Abbott, USA). HBsAg below $0.05 \mathrm{IU} / \mathrm{ml}$, anti-HBs below $10.0 \mathrm{mIU} / \mathrm{ml}$, HBeAg and anti-HBc below the signal/cutoff ratio of 1.0 were considered negative. HBVDNA was analyzed using a real-time PCR assay using COBAS AmpliPrep/COBAS TaqMan 48 analyser (Roche, Switzerland), HBVDNA<12 $\mathrm{IU} / \mathrm{ml}$ was considered negative. HBV genotypes were analyzed using the TRUGENE HBV genotyping kit (Siemens medical solutions diagnostics, Saint Denis, France).

Statistical analysis was performed using the Statistical Package for the Social Sciences (version 17.0, SPSS, Chicago, IL, USA). Data were analyzed by Fisher's exact test and calculated odds ratio (OR) value and 95\% confidence interval $(\mathrm{CI})$. Statistically significant differences were defined as $\mathrm{P}<0.05$.

\section{Results}

The prevalence of $\mathrm{HBsAg}$, anti-HBc and anti-HBs among pregnant women

A total of 4,536 pregnant women aged 16 - 45 years were screened for HBsAg. The prevalence of HBsAg among pregnant women was $5.49 \%$ (249/4536). The prevalence of HBsAg among pregnant women older than 20 years $(5.64 \%)$ was 4.54 times that among pregnant women younger than 20 years $(1.30 \%)(O R=4.54,95 \%$ CI: 1.12 18.43). This higher prevalence of HBsAg among pregnant women older than 20 years was significant higher compared to pregnant women younger than 20 years $(\mathrm{P}<0.05)$ (Table 1$)$.

The prevalence of anti-HBc among pregnant women was $29.65 \%(1345 / 4536)$. The prevalence of anti-HBc among pregnant women older than 20 years $(30.44 \%)$ was 5.69 times that among pregnant women younger than 20

Table 1 The prevalence of $\mathrm{HBsAg}$, anti-HBc and anti-HBs among pregnant women in the different age groups

\begin{tabular}{|c|c|c|c|c|c|c|c|c|c|}
\hline \multirow[t]{2}{*}{ Age group } & \multicolumn{2}{|c|}{ HBsAg } & \multirow[t]{2}{*}{ OR } & \multicolumn{2}{|c|}{ anti-HBC } & \multirow[t]{2}{*}{ OR } & \multicolumn{2}{|c|}{ anti-HBs } & \multirow[t]{2}{*}{ OR } \\
\hline & Positive & Negative & & Positive & Negative & & Positive & Negative & \\
\hline less than 20 years old & 2 & 152 & $1.0^{@}$ & 11 & 143 & $1.0^{@}$ & 107 & 47 & $1.0^{@}$ \\
\hline$n=154$ & (1.30\%) & (98.70\%) & & (7.14\%) & (92.86\%) & & (69.48\%) & (30.54\%) & \\
\hline older than 20 years & 247 & 4135 & 4.54 & 1334 & 3048 & 5.69 & 2549 & 1833 & 0.61 \\
\hline$n=4382$ & (5.64\%) & (94.36\%) & & (30.44\%) & (69.56\%) & & (58.17\%) & (41.83\%) & \\
\hline total & 249 & 4287 & & 1345 & 3191 & & 2656 & 1880 & \\
\hline$n=4536$ & $(5.49 \%)$ & $(94.51 \%)$ & & $(29.65 \%)$ & $(70.35 \%)$ & & $(58.55 \%)$ & $(41.45 \%)$ & \\
\hline$x^{2}$ & \multicolumn{2}{|c|}{4.59} & & \multicolumn{2}{|c|}{37.61} & \multicolumn{4}{|c|}{7.38} \\
\hline$P$ & \multicolumn{2}{|c|}{$<0.05$} & & \multicolumn{2}{|c|}{$<0.01$} & \multicolumn{4}{|c|}{$<0.05$} \\
\hline
\end{tabular}


Table 2 HBeAg status and HBVDNA load among HBsAg positive pregnant women

\begin{tabular}{cccc}
\hline $\begin{array}{c}\text { HBVDNA } \\
\mathbf{I U} / \mathbf{m l}\end{array}$ & $\begin{array}{c}\text { HBeAg positive } \\
\mathbf{n = 1 6 7}\end{array}$ & $\begin{array}{c}\text { HBeAg negative } \\
\mathbf{n}=\mathbf{8 2}\end{array}$ & $\begin{array}{c}\text { Total } \\
\mathbf{n}=\mathbf{2 4 9}\end{array}$ \\
\hline$<12$ & $0(0 \%)$ & $45(54.88 \%)$ & $45(18.07 \%)$ \\
$(12-50)$ & $2(1.20 \%)$ & $9(39.02 \%)$ & $11(4.42 \%)$ \\
$\left(50-<10^{7}\right)$ & $128(76.64 \%)$ & $28(6.10 \%)$ & $156(62.65 \%)$ \\
$\left(>10^{7}\right)$ & $37(22.16 \%)$ & $0(0 \%)$ & $37(14.86 \%)$ \\
\hline
\end{tabular}

years $(7.14 \%)(O R=5.69,95 \% \mathrm{CI}: 3.07 \sim 10.54)$. This higher prevalence of anti-HBc among pregnant women older than 20 years was significant higher compared to pregnant women younger than 20 years $(\mathrm{P}<0.01)$ (Table 1$)$.

The prevalence of anti-HBs among pregnant women was $58.55 \%(2656 / 4536)$. The prevalence of anti-HBs among pregnant women older than 20 years $(58.17 \%)$ was 0.61 times that among pregnant women younger than 20 years $(69.48 \%)(O R=0.61,95 \% C I: 0.43 \sim 0.87)$. This lower prevalence of anti-HBs among pregnant women older than 20 years was significant lower compared to pregnant women younger than 20 years $(\mathrm{P}<0.05)$ (Table 1$)$.

\section{HBeAg status and HBVDNA load among HBsAg positive pregnant women}

HBeAg and HBVDNA were analyzed among the 249 HBsAg positive pregnant women. Of the 249 women, 167 (67.07\%) were HBeAg positive and 204 (81.93\%) were HBVDNA positive. Of the 204 HBVDNA positive women, only 37 (14.86\%) had HBVDNA $>10^{7} \mathrm{IU} / \mathrm{ml}$. All pregnant women with HBVDNA $>10^{7} \mathrm{IU} / \mathrm{ml}$ were $\mathrm{HBeAg}$ positive and all those who were HBVDNA negative were $\mathrm{HBeAg}$ negative (Table 2).

\section{HBV infection of infants}

There were 249 infants whose mothers were HBsAg positive and were vaccinated with standard immunoprophylaxis and followed up at 7 months of age. There were 214 (85.94\%) infants who tested anti-HBs positive only. There were 12 (4.82\%) infants who were HBsAg and HBVDNA positive, and their mothers were $\mathrm{HBeAg}$ positive and HBVDNA $>10^{7} \mathrm{IU} / \mathrm{ml}$ (Table 3 ). There were 2 (16.67\%) infants who were anti-HBs positive among the $12 \mathrm{HBsAg}$ positive infants.The anti-HBs titers were $547.25 \mathrm{mIU} / \mathrm{ml}$ and $1224.58 \mathrm{mIU} / \mathrm{ml}$, respectively.

HBV genotypes among pregnant women and their infants Only genotypes B and C had been found among 165 pregnant women (Table 4). The 165 pregnant women were divided into two groups on the basis of their infants being with or without HBV infection. There were 12 infants who were HBsAg positive and had the same HBV genotypes as their mothers. Genotype $C$ was present in 85 pregnant women. Genotype $C$ was present in 10 pregnant women whose infants were infected with HBV and 75 pregnant women whose infants were not infected with HBV. Genotype B was present in 2 pregnant women whose infants were infected with HBV. There was a significant difference between pregnant women whose infants were infected with $\mathrm{HBV}$ and those without $\mathrm{HBV}$ infection $(\mathrm{P}=0.04<0.05)$. Genotype $\mathrm{C}$ was present in 2 anti-HBs and HBsAg positive infants.

\section{Discussions}

There are more than 130 million chronic HBV carriers in China, 30\%-50\% of whom are thought to have acquired HBV infection from mother-to-child transmission [5-7]. Preventing the mother-to-child transmission route can significantly decrease $\mathrm{HBV}$ infection among infants and

Table 3 Serological and virological profile for the 12 infected mother-infant pairs

\begin{tabular}{|c|c|c|c|c|c|c|c|c|c|c|}
\hline \multirow[t]{2}{*}{ No. } & \multicolumn{5}{|c|}{ Mothers } & \multicolumn{5}{|c|}{ Infants } \\
\hline & HBsAg & HBeAg & anti-HBc & anti-HBs & HBVDNA (IU/ml) & HBsAg & HBeAg & anti-HBc & anti-HBs & HBVDNA (IU/ml) \\
\hline 1 & + & + & + & - & $5.56 \times 10^{7}$ & + & + & + & - & $1.14 \times 10^{7}$ \\
\hline 2 & + & + & + & - & $5.49 \times 10^{8}$ & + & + & + & + & $1.73 \times 10^{7}$ \\
\hline 3 & + & + & + & - & $2.37 \times 10^{8}$ & + & + & + & - & $2.80 \times 10^{8}$ \\
\hline 4 & + & + & + & - & $4.12 \times 10^{8}$ & + & + & + & + & $2.21 \times 10^{7}$ \\
\hline 5 & + & + & + & - & $2.89 \times 10^{9}$ & + & + & + & - & $9.63 \times 10^{8}$ \\
\hline 6 & + & + & + & - & $2.16 \times 10^{7}$ & + & + & + & - & $6.98 \times 10^{7}$ \\
\hline 7 & + & + & + & - & $2.63 \times 10^{8}$ & + & + & + & - & $2.94 \times 10^{7}$ \\
\hline 8 & + & + & + & - & $2.03 \times 10^{8}$ & + & + & + & - & $7.82 \times 10^{7}$ \\
\hline 9 & + & + & + & - & $6.61 \times 10^{7}$ & + & + & + & - & $2.24 \times 10^{7}$ \\
\hline 10 & + & + & + & - & $7.17 \times 10^{7}$ & + & + & + & - & $1.15 \times 10^{7}$ \\
\hline 11 & + & + & + & - & $1.93 \times 10^{7}$ & + & + & + & - & $3.77 \times 10^{7}$ \\
\hline 12 & + & + & + & - & $2.59 \times 10^{7}$ & + & + & + & - & $6.42 \times 10^{7}$ \\
\hline
\end{tabular}


Table 4 HBV Genotypes among 165 pregnant women

\begin{tabular}{lcc}
\hline Group & Genotype B & Genotype C \\
\hline $\begin{array}{l}\text { Infants with HBV infection } \\
n=12\end{array}$ & $\mathbf{2}$ & $\mathbf{1 0}$ \\
Infants without HBV infection & $\mathbf{7 8}$ & $\mathbf{7 5}$ \\
$\mathrm{n}=153$ & & \\
total & $\mathbf{8 0}$ & $\mathbf{8 5}$ \\
$\mathrm{n}=165$ & & \\
\hline $\mathrm{X}^{2}=3.96, P<0.05$. & &
\end{tabular}

can relieve the HBV disease burden. In China, 90\% of HBV mother-to-child transmission can be prevented by the administration of immunoprophylaxis with HBIG and the hepatitis $B$ vaccine $[8,9]$. It has been confirmed that the failure of immunoprophylaxis is mainly associated with maternal seropositivity for HBeAg and high viral load [10-12]. It is recommended that HBsAg-positive pregnant women who are $\mathrm{HBeAg}$ positive and have a high viral load be given antivirals in late pregnancy to suppress virema [13-15]. Thus, it is important to survey chronic HBV infection among pregnant women and their infants and find other reasons for immunoprophylaxis failure.

There were a total of 4,536 pregnant women aged 16 45 years who were enrolled in our study. We showed that the prevalence of HBsAg among pregnant women in Shenyang was $5.49 \%$, which is lower than the overall prevalence of HBsAg among pregnant women in China (8.16\%) [16]. The prevalence of $\mathrm{HBsAg}$, anti-HBc and anti-HBs among pregnant women older than 20 years of age was 4.54, 5.69 and 0.61 times that among pregnant women younger than 20 years, respectively. The difference in prevalence of HBsAg, anti-HBc and anti-HBs between pregnant women older than 20 years versus younger than 20 years of age was significant. This could be related to immunoprophylaxis having been universally administered to infants since 1990, which could improve immunity against $\mathrm{HBV}$ and decrease $\mathrm{HBV}$ infection among their infants.

Among HBsAg positive pregnant women, the majority were $\mathrm{HBeAg}$ positive and HBVDNA positive $(67.07 \%$ and $81.93 \%$, respectively), a minority (14.86\%) had a high viral load. Only 12 (4.82\%) infants were HBsAg and HBVDNA positive, and their mothers were also $\mathrm{HBeAg}$ positive and had HBVDNA $>10^{7} \mathrm{IU} / \mathrm{ml}$, which confirmed previous reports. These HBeAg positive and high viral load pregnant women should be offered antiviral treatment during late pregnancy to prevent HBV mother-to-child transmission. There were 2 infants who were both anti-HBs and HBsAg positive. It was reported that the infants were infected with mutant strains which were transmitted from their mothers [17-20]. We should further test sequence analysis to support it and manufacture mutant strain vaccines to prevent HBV mother-to-child transmission.
HBV has been classified into eight genotypes, designated as $\mathrm{A}-\mathrm{H}$, based on intergenotypic divergence of at least $8 \%$ in the complete nucleotide sequence or more than $4 \%$ in the S gene [21-27]. HBV genotypes have distinct geographical distributions and correlate with the severity of liver diseases [28-30]. Are HBV genotypes of great importance in $\mathrm{HBV}$ mother-to-child transmission and/or affect the immunization success with HBIG and hepatitis $B$ vaccine? Only genotypes $B$ and $C$ were found among 165 pregnant women. There was a significant difference in genotypes between the pregnant women whose infants were HBV infected and those without HBV infection. Genotype $C$ might be a risk factor for HBV mother to child transmission. It should be recommended that pregnant women who are $\mathrm{HBeAg}$ positive and have a high viral load be tested for HBV genotypes.

\section{Conclusions}

There was a significant decline in the HBsAg prevalence among pregnant women and their infants in Shenyang, which might be attributed to universal implementation of immunoprophylaxis since 1990. Genotype C might be a risk factor for HBV mother to child transmission.

\section{Ethical approval}

The Institutional Ethics Committee of Shengjing Hospital of China Medical University approved the study (No.2010PS29K) and the study conformed to the Helsinki declaration of 1996. Informed consent was obtained from all the study subjects prior to the study.

\section{Abbreviations}

(HBV): Hepatitis B virus; (HBsAg): Hepatitis B surface antigen;

(HBeAg): Hepatitis B e antigen; (anti-HBs): Hepatitis B surface antibody; (anti-HBc): Hepatitis B core antibody; (HBIG): Hepatitis B immunoglobulin.

\section{Competing interests}

The authors declare that they have no competing interests.

\section{Authors' contributions}

YD and XGD designed, executed and coordinated the study. YD, QJS and LM contributed in the sample acquirement and laboratory analysis. YD and XGD participated in the drafting of the manuscript and literature search. All authors read and approved the final manuscript.

\section{Acknowledgement}

We extend our thanks to all pregnant women involved in our study.

\section{Funding}

This study was supported by China National Fund of Ministry of Science and Technology (30972612), Liaoning Provincial Fund of Provincial Department of Science and Technology (2009225010-7). And this study was also supported by Shenyang Science and Technology Program No. F10-205-1-10.

Received: 8 March 2012 Accepted: 21 December 2012

Published: 7 January 2013

\section{References}

1. Lavanchy D: Worldwide epidemiology of HBV infection, disease burden, and vaccine prevention. J Clin Virol 2005, 34(Suppl 1):S1-S3.

2. Zuckerman JN, Zuckerman AJ: Current topics in hepatitis B. J Infect 2000, 41:130-136 
3. Michielsen P, Van Damme P: Viral hepatitis and pregnancy. Acta Gastroenterol Belg 1999, 62(1):21-29.

4. Liang X, Bi S, Yang W, et al: Epidemiological serosurvey of hepatitis B in China-declining HBV prevalence due to hepatitis B vaccination. Vaccine 2009, 27(47):6550-6557.

5. Cacciola I, Cerenzia G, Pollicino T, et al: Genomic heterogeneity of hepatitis B virus (HBV) and outcome of perinatal HBV infection. $J$ Hepatol 2002, 36(3):426-432

6. Papadakis MA, Elefsiniotis IS, Vlahos $G$, et al: Intrauterine-transplacental transmission of hepatitis $B$ virus (HBV) from hepatitis $B$ e antigen negative (precore mutant, G1896A) chronic HBV infected mothers to their infants, Preliminary results of a prospective study. J Clin Virol 2007, 38:181-183.

7. Zhang SL, Yue YF, Bai GQ, Shi L, Jiang H: Mechanism of intrauterine infection of hepatitis B virus. World J Gastroenterol 2004, 10(3):437-438.

8. Dong ZQ, Zhang XZ, Gu XH, et al: A randomized controlled trial on interruption of HBV transmission in uterus. Chin J Pediatr 2002. 40(8):478-480

9. Guo Y, Liu JQ, Meng L, et al: Survey of HBsAg-postive pregnant women and their infants regarding measures to prevent maternal-infantile transmission. BMC Infect Dis 2010, 10:26.

10. Shao ZJ, Lei Zhang $L, X u J Q$, et al: Mother-to-infant transmission of hepatitis B virus: a Chinese experience. J Med Virol 2011, 83:791-795.

11. Soderstrom A, Norkrans G, Lindh M: Hepatitis B virus DNA during pregnancy and post partum: aspects on vertical transmission. Scand J Infect Dis 2003, 35(11-12):814-819.

12. Wang $Z$, Zhang J, Yang $H$, et al: Quantitative analysis of HBV-DNA level and $\mathrm{HBeAg}$ titer in hepatitis $B$ surface antigen positive mothers and their babies: HBeAg passage through the placenta and the rate of decay in babies. J Med Virol 2003, 71(3):360-366.

13. Van Zonneveld M, Van Nunen $A B$, Neiesters $H G$, et al: Lamivudine treatment during pregnancy to prevent perinatal transmission of hepatitis B infection. J Viral Hepat 2003, 10(4):294-297.

14. Xu WM, Cui YT, Wang $L$, et al: Lamivudine treatment in late pregnancy to prevent perinatal transmission of hepatitis B infection: a multicentre, randomized, double-blind, placebo-controlled study. J Viral Hepat 2009, 16(2):94-103.

15. Zhang $L$, Wang $L$ : Blocking intrauterine infection by telbivudine in pregnant chronic hepatitis B patients. Zhonghua Ganzangbing Zazhi 2009, 17(8):561-563.

16. Centers for Disease Control and Prevention: Progress in hepatitis B prevention through universal infant vaccination-China, 1997-2006. MMWR Morb Mortal Wkly Rep 2007, 56:441-445.

17. Domingo E: Quasispecies: concepts and implications for virology. Virology 2006, 299:17-20

18. Domingo E, Gomez J: Quasispecies and its impact on viral hepatitis. Virus Res 2007, 127(2):131-150.

19. Gibb R, Nimmo GR, O'Loughlin $P$, et al: Detection of HBsAg mutatants in a population with a low prevalence of hepatitis B virus infection. J Med Virol 2007, 79(4):351-355.

20. Gerlich WH: Breakthrough of hepatitis B virus escape mutation after vaccination and virus reactivation. J Clin Virol 2006, 36(Suppl1):S18-S22.

21. Okamoto H, Tsuda F, Sakugawa H, Sastrosoewignjo RI, Imai M, Miyakawa $Y$, Mayumi M: Typing hepatitis B virus by homology in nucleotide sequence: comparison of surface antigen subtypes. J Gen Virol 1988 69:2575-2583

22. Norder H, Couroucé AM, Magnius LO: Complete genomes, phylogenetic relatedness, and structural proteins of six strains of the hepatitis B virus, four of which represent two new genotypes. Virology 1994, 198:489-503.

23. Kato H, Orito E, Sugauchi F, Ueda R, Gish RG, Usuda S, Miyakawa Y, Mizokami M: Determination of hepatitis $B$ virus genotype $G$ by polymerase chain reaction with hemi-nested primers. J Virol Methods 2001, 98:153-159.

24. Arauz-Ruiz P, Norder H, Robertson BH, Magnius LO: Genotype H: a new Amerindian genotype of hepatitis $B$ virus revealed in Central America. J Gen Virol 2002, 83:2059-2073.

25. Stuyver L, De Gendt S, Van Geyt C, Zoulim F, Fried M, Schinazi RF, Rossau R: A new genotype of hepatitis $B$ virus: complete genome and phylogenetic relatedness. J Gen Virol 2000, 81:67-74

26. Bartholomeusz A, Schaefer S: Hepatitis B virus genotypes: comparison of genotyping methods. Rev Med Virol 2004, 14:3-16.
27. Usuda S, Okamoto H, Tanaka T, Kidd-Ljunggren K, Holland PV, Miyakawa Y, Mayumi M: Differentiation of hepatitis $B$ virus genotypes $D$ and $E$ by ELISA using monoclonal antibodies to epitopes on the preS2-region product. J Virol Methods 2000, 87:81-89.

28. Kao JH, Chen PJ, Lai MY, Chen DS: Hepatitis B genotypes correlate with clinical outcomes in patients with chronic hepatitis B. Gastroenterology 2000, 118:554-559.

29. Kobayashi M, Arase Y, Ikeda K, Tsubota A, Suzuki Y, Saitoh S, Kobayashi M, Suzuki F, Akuta N, Someya T, Matsuda M, Sato J, Kumada H: Clinical characteristics of patients infected with hepatitis $B$ virus genotypes $A, B$, and C. J Gastroenterol 2002, 37:35-39.

30. Ding X, Mizokami M, Yao G, Xu B, Orito E, Ueda R, Nakanishi M: Hepatitis B virus genotype distribution among chronic hepatitis $B$ virus carriers in Shanghai, China. Intervirology 2001, 44:43-47.

doi:10.1186/1743-422X-10-17

Cite this article as: Ding et al:: Chronic HBV infection among pregnant women and their infants in Shenyang, China. Virology Journal 2013 10:17.

\section{Submit your next manuscript to BioMed Central and take full advantage of:}

- Convenient online submission

- Thorough peer review

- No space constraints or color figure charges

- Immediate publication on acceptance

- Inclusion in PubMed, CAS, Scopus and Google Scholar

- Research which is freely available for redistribution

Submit your manuscript at www.biomedcentral.com/submit
C) Biomed Central 